\title{
RECURRENT VENOUS TROMBOEMBOLISM AND THE INEFFECTIVENESS OF RIVAROXABAN IN PATIENT WITH POLYMOSITE - CASE REPORT
}

Osvaldo Luiz Camata Junior (Universidade de São Paulo, São Paulo, SP, Brasil), Cássio Murilo Trovo Hidalgo Filho (Hospital do Servidor Público Municipal, Sâo Paulo, SP, Brasil), Pérola Goberstein Lerner (Hospital do Servidor Público Municipal, Sâo Paulo, SP, Brasil), Tatiane Goberstein Lerner Wakrat (Hospital do Servidor Público Municipal, São Paulo, SP, Brasil)

\section{BACKGROUND}

Patients with Inflammatory Myopathies (IM) are up to nine times more likely to present venous tromboembolism (VTE) than the general population. However, the recurrent of this event is rare in these patients. Recommendations for treatment of VTE in IM are extrapolated from studies of Antiphospholipid Antibody Syndrome (APS). Therefore, we report the case of recurrent VTE in a Polymyositis patient who was being treated with Rivaroxaban.

\section{CASE REPORT}

A 65-year-old male patient with a previous history of pulmonary thromboembolism (PTE) for four years, was admitted to the hospital with proximal muscle weakness and pain in the proximal region of the limbs started 20 days ago. During the first days of hospitalization, he presented dyspnea, desaturation and progressive dysphagia. Laboratory tests showed CPK (Creatinine Phosphokinase) of $8771 \mathrm{U} / \mathrm{L}$, aldolase of $7.7 \mathrm{U} / \mathrm{L}$ and anti $\mathrm{JO} 1$ of $111 \mathrm{U} / \mathrm{ml}$ and high resolution computed tomography (HRCT) of chest with interstitial bilateral opacities (Interstitial Pneumonia not specified) and Pneumonia in Organization. Diagnosed with Polymyositis according to ACR / EULAR 2017 criteria, the treatment was instituted with prednisone $1 \mathrm{mg} / \mathrm{kg} /$ day and azathioprine $1.5 \mathrm{mg} / \mathrm{kg}$. On the sixth day of hospitalization the patient developed extensive bilateral deep vein thrombosis (DVT), even in the presence of prophylactic anticoagulation. Prescribed full anticoagulation with Enoxaparin 1mg/kg every 12 hours and Warfarin $5 \mathrm{mg}$ / day thereafter. The patient was discharged in use of prednisone $0.5 \mathrm{mg} / \mathrm{kg}$ / day and azathioprine $200 \mathrm{mg}$ / day. At a later outpatient evaluation, the hypothesis of APS, thrombophilia (hereditary and acquired) and cancer were excluded, and Rivaroxaban $15 \mathrm{mg}$ / day was chosen as the anticoagulation drug, because of the important lability of the International Normalized Ratio (NR) during treatment and difficulty in collecting exams for laboratory control. After three months the change to Rivaroxaban, this patient presented new acute PTE, without evidence of disease activity at the time. After further evaluation, the possible secondary causes of the thromboembolic event, such as cancer, hereditary thrombophilia and APS, were excluded. We opted for the suspension of Rivaroxaban and reintroduction of the vitamin $\mathrm{K}$ antagonist.

\section{CONCLUSION}

The association of polymyositis without the evidence of disease activity with multiple thromboembolic events, makes this case especially rare. In addition, the recurrence of VTE during the use of Rivaroxabana, suggests possible inefficacy of this medication in patients with VTE and Autoimmune Diseases. 